\title{
O SIGNIFICADO DA CAPACITAÇÃO EM TERAPIA COMUNITÁRIA INTEGRATIVA NA VIDA DOS TERAPEUTAS COMUNITÁRIOS
}

\author{
Maria Lucia de Andrade REIS* \\ Marilene GRANDESSO **
}

RESUMO: Com esse estudo pretendemos compreender o significado da capacitação em Terapia Comunitária Integrativa (TCI) para os terapeutas comunitários e como esse significado foi construído. Para isso realizamos uma pesquisa qualitativa construindo um contexto de investigação priorizando a escuta de terapeutas comunitários sobre o seu processo de capacitação em TCI. Sete terapeutas comunitários participaram dessa pesquisa. Dada a natureza dessa investigação centrada no campo do significado, realizamos entrevistas organizadas como conversas dialógicas em torno de alguns temas de interesse de acordo com os objetivos acima mencionados. As informaçôes obtidas foram analisadas de acordo com a poética social, que convida o pesquisador a ressaltar aspectos marcantes na sua conversação com os participantes. Compreender o sentido da capacitação em TCI para a vida dos terapeutas comunitários e os aspectos envolvidos nesses resultados poderá favorecer o entendimento do impacto do processo de formação para os envolvidos, contribuindo com a rede de polos formadores em TCI creditados pela ABRATECOM, América Latina e Europa.

PALAVRAS-CHAVE: Terapia Comunitária Integrativa. Significado. Capacitação.

* CAIFCOM - Centro de Atendimento, Ensino e Pesquisa do Indivíduo, Família e Comunidade. Porto Alegre - RS - Brasil. 90560-005. INTERFACI - Instituto de Terapia: Família, Casal, Comunidade e Indivíduo da PUC-SP. São Paulo - SP - Brasil. 04089-000 malureis@uol.com.br.

** INTERFACI - Instituto de Terapia: Família, Casal, Comunidade e Indivíduo da PUCSP. São Paulo - SP - Brasil. 04089-000 - mgrandesso@uol.com.br. 


\section{Introdução}

No Brasil, segundo FREIRE (1983, p.65) vivíamos um momento de transiçáo, de uma sociedade fechada, de estrutura colonial, "[...] escravocrata, sem povo, reflexa, antidemocrática”, para uma sociedade aberta, disposta a mobilizaçáo e engajamento em movimentos sociais, lutando não só por melhorias na qualidade da educação, mas também em questóes mais amplas, como a defesa dos Direitos Humanos. (REIS; SALERNO, 2011, p. 364).

A Terapia Comunitária Integrativa (TCI) surgiu nos anos oitenta, na comunidade do Pirambu, em Fortaleza - Ceará. Essa prática foi criada pelo Dr. Adalberto de Paula Barreto, psiquiatra, teólogo, antropólogo e professor da Faculdade de Medicina da Universidade Federal do Ceará (UFC), como uma proposta para atender às necessidades de saúde da população daquela comunidade (BARRETO, 2008).

Ao estruturar a metodologia proposta pela TCI, Barreto (2008) ancorou suas bases teóricas em cinco grandes eixos: o Pensamento Sistêmico, a Teoria da Comunicação, a Antropologia Cultural, a noção de Resiliência e a Pedagogia de Paulo Freire. Quanto ao contexto de conversação, a TCI foi estruturada em etapas progressivas que permitem dar conta do processo, tornando cada encontro um acontecimento estruturado com começo, meio e finalização.

Barreto (2008) propôs cinco etapas para a realização da TCI junto à comunidade: acolhimento, escolha do tema, contextualização, problematização e encerramento (rituais de agregação, fechamento). Além dessas etapas, inspirado no pensamento freireano, uma sexta etapa - apreciaçáo da TCI realizada - foi criada exclusivamente para os terapeutas comunitários, sem a presença da comunidade, para a avaliação do processo, tornando a formação do terapeuta um processo contínuo de aprendizagem. Cada uma dessas etapas tem um sentido próprio e, no conjunto, constroem as possibilidades para uma conversação transformadora, edificada sobre os recursos e estratégias de ação dos membros da comunidade.

A TCI possui como uma de suas características a simplicidade da sua metodologia. Segundo Grandesso (2005, p. 105),

[...] contudo, não se trata de um modelo de uso indiscriminado, requerendo capacitação e supervisão. Ser simples náo quer dizer ser simplista. Existe todo um embasamento teórico e, especial- 
mente para quem náo tem uma prática anterior como terapeuta, requer uma atenção especial para a prática e manejo de grupos.

Após quase três décadas de experiência, muitas pesquisas já foram realizadas para averiguar a eficácia de sua proposta e investigar o impacto da TCI: Camargo e Franklin (2013), Lazzarini e Grandesso (2013), Braga et al (2013), Silva e Almeida (2013), Holanda et al (2013), Oliveira e Dias (2013), Andrade et al (2013), Guimarães e Ferreira Filha (2013), Rocha e Ferreira Filha (2013), Carício et al (2013), Morais e Dias (2013), Sobreira e Miranda (2013). Esses estudos apontam que essa metodologia possibilita a mudança de práticas profissionais, reforça a autoestima e, fortalece vínculos positivos, promovendo as redes solidárias de apoio e otimizando os recursos da comunidade, aspecto este particularmente relevante quando a rede de serviços existente se mostra insuficiente para atender às demandas crescentes.

Todas essas experiências, transformadas em artigos, monografias, dissertaçóes, teses e livros, possibilitaram que hoje em dia a Terapia Comunitária Integrativa seja uma metodologia reconhecida como uma prática integrativa complementar e uma estratégia na atenção básica na saúde mental, recomendada em diversas publicaçôes do Ministério da Saúde, especialmente as mais recentes, como Cadernos de Atenção Básica - Saúde Mental, de 2013, e Cadernos de Atenção Básica - NASF, de 2014.

Em relação às açôes no exterior, hoje a TCI está presente em diversos países da América do Sul, como na Argentina, Bolívia, Chile, Equador, Uruguai e Venezuela. Desde a década de 90 foi difundida para países da Europa, como a França e Suíça e mais recentemente para a Alemanha, Dinamarca e Itália. Fruto dessa mobilização foi criada a Associação Europeia de TCI e a Associação Suíça de TCI.

No continente africano, durante o ano de 2011, foi realizada uma capacitação em TCI em três regiôes distintas - norte (Nampula), centro (Zambézia) e sul (Maputo), através de uma parceria entre os Ministérios da Saúde do Brasil e de Moçambique ${ }^{1}$.

Disponível em: <http://consciencia.net/a-terapia-comunitaria-em-mocambique-pormariano-pedroza/>. Acesso em: $8 \mathrm{dez} .2015$. 


\section{A Capacitação em TCI no Brasil: compartilhando nossa trajetória}

As capacitaçôes em TCI na década de 90 eram oferecidas somente pelo Departamento de Saúde Comunitária e a Pró-Reitoria de Extensão da Universidade Federal do Ceará (UFC), que desenvolveram o Modelo de Atenção Primária em Saúde Mental, através do Projeto Quatro Varas. Até o início dos anos 90, a capacitação era voltada basicamente à população do estado do Ceará. De fato, a formação em TCI no âmbito nacional começou nos meados dos anos 90, a partir de uma parceria entre a UFC e a Pastoral da Criança, com o objetivo de capacitar os agentes da Pastoral em Terapia Comunitária, como forma de ampliar suas possibilidades de atenção às famílias e comunidades.

Em 2003, foi realizado o I Congresso Brasileiro de Terapia Comunitária Integrativa, em Morro Branco/CE, organizado pelo Movimento Integrado de Saúde Comunitária/CE (MISMEC/CE), em parceria com a UFC, reunindo profissionais de várias partes do país, possibilitando o intercâmbio de experiências sobre a prática de TCI, além de traçar linhas de pesquisa futuras e o planejamento de açôes mobilizadoras (BARRETO; CAMAROTTI, 2003).

Como resultado desse processo, em 2004, no II Congresso Brasileiro de TCI, em Brasília/DF, organizado pelo MISMEC/DF, foi criada a Associação Brasileira de Terapia Comunitária Integrativa (ABRATECOM), tendo como uma de suas missóes nortear a expansão da formação em TCI, uma vez que haviam sido constituídos vários polos formadores ${ }^{2}$, instituiçôes responsáveis pela capacitação, espalhados pelo país. $\mathrm{Na}$ ocasião, poucas instituições eram reconhecidas como polos formadores e o diálogo entre os representantes presentes no II Congresso, foi sensível à importância de uma organização institucional que pudesse dar sustentação e visibilidade da prática da TCI, resultando na ABRATECOM.

A regulamentação dos cursos de TCI, no período de 2004 a 2012, previa uma carga horária mínima de $360 \mathrm{~h} / \mathrm{a}$ para a capacitação, assim distribuídas: $80 \mathrm{~h} / \mathrm{a}$ destinadas à parte teórica, $80 \mathrm{~h} / \mathrm{a}$ para as vivências

\footnotetext{
2 Os Polos Formadores de TCI são constituídos por instituiçốes e/ou associaçóes efetivamente envolvidas com atividades práticas de TCI e áreas afins, pautando-se pelo Regimento Interno do CDC, respeitados os Estatutos da ABRATECOM, assim como toda a legislaçấo vigente e pertinente. Cabe exclusivamente aos Polos Formadores promover a capacitação em TCI e áreas afins, conforme prevê esse documento.
} 
terapêuticas, $120 \mathrm{~h} / \mathrm{a}$ de estágio prático, correspondendo a condução de 48 rodas de TCI e 80h/a de encontros de intervisão, nome que elegemos para nos referir à prática tradicional de supervisão ${ }^{3}$.

Em maio de 2013 definiu-se 240h/a como carga horária mínima, como consta no regimento atual do CDC, sendo 50h/a destinadas aos aspectos teóricos, 50h/a para as vivências terapêuticas, $80 \mathrm{~h} / \mathrm{a}$ para os encontros de intervisão e $60 \mathrm{~h} / \mathrm{a}$ de estágio prático, correspondendo à condução de trinta rodas de TCI, com duração de $2 \mathrm{~h}$ cada.

Atualmente, os cursos de capacitação em TCI estão estruturados em módulos, compostos por momentos presenciais e de dispersão. Nos encontros presenciais são desenvolvidos como conteúdo programático, os eixos teóricos que embasam a TCI, tendo como principal referência, o livro Terapia Comunitária passo a passo, de autoria do Prof. Dr. Adalberto de Paula Barreto (2008).

As vivências terapêuticas oportunizadas nos encontros presencias módulos teóricos e intervisóes - têm como objetivo trabalhar a pessoa do terapeuta, como também proporcionar ao futuro terapeuta vivências que the permitam conhecer suas sensibilidades e competências, para que ele, ao acolher a sua dor e a sua história, acolha melhor a história e a dor do outro nas rodas de TCI.

A base desse trabalho com as dinâmicas vivenciais são os seis pilares da autoestima (BRANDEN, 1997): viver conscientemente, autoaceitação, autorresponsabilidade, autoafirmação, viver intencionalmente e integridade pessoal.

Durante o processo de capacitação em TCI, são destinadas 80h/a para os encontros presenciais de intervisão. As atividades de intervisão são partes do processo de formação e diferenciam-se da supervisão tradicional, por serem uma atividade construída entre intervisores e terapeutas em formação a partir de necessidades advindas das distintas realidades, além de ser um momento para refletir sobre a prática e descobrir elementos para subsidiar as discussóes dos módulos posteriores. Durante o processo de capacitação, o terapeuta comunitário em formação é incentivado e assistido, a partir do $1^{\circ}$. módulo, para iniciar a conduçáo de rodas de TCI junto a uma comunidade, preferencialmente em duplas. O acompanhamento ao estágio prático é feito presencialmente nos encontros de intervisão e à distância, através do preenchimento das Fichas de Registro das Rodas de TCI.

\footnotetext{
3 Para maiores informaçôes sobre a mudança do termo supervisão para intervisão, sugerimos o artigo de Reis (2010).
} 
Ao final de todo esse processo receberão certificado, chancelado pela ABRATECOM, o participante que atender aos requisitos exigidos relacionados a $75 \%$ de presença nos encontros teóricos, vivências e encontros de intervisão e $100 \%$ das rodas de TCI previstas como estágio prático.

\section{Problematizando o tema desta investigaçáo}

Viver é afinar o instrumento, de dentro prá fora, de fora prá dentro, A toda hora, a todo o momento, De dentro prá fora, de fora prá dentro, A toda hora, a todo o momento, De dentro prá fora, de fora prá dentro.

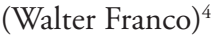

Como em uma roda de TCI, após a etapa da contextualização, que fizemos aqui com a nossa introdução ao tema deste estudo, agora seria o momento de apresentar o mote, ou seja, a pergunta-chave que serviu de convite para nossa investigação. Mas antes, queremos dar destaque para uma importante contribuição feita por Rique (2010), em sua dissertação de Mestrado Terapia Comunitária: um encontro que transforma o jeito de conduzir a vida, quando investigou as transformaçóes produzidas a partir da Capacitação em TCI para trabalhadoras da Estratégia de Saúde da Família, da cidade de João Pessoa/PB:

Percebeu-se ao longo deste estudo que as colaboradoras identificaram processos de mudança e crescimento provocados pela sua participação na formação em TC. Ao se aproximarem nas suas histórias de vida, de reflexóes desencadeadas pelos trabalhos sobre o resgate pessoal e familiar de cada um, como também, através de suas crises, sofrimentos e vitórias que proporcionaram uma investigação interior buscando um novo reencontro consigo mesmo (RIQUE, 2010, p.103).

Consideramos importante esclarecer que não é em busca de depoimentos como esses que essa pesquisa se dirigiu. $\mathrm{O}$ que moveu esse trabalho foi buscar compreender o que acontece no processo de capaci-

Trecho da música Serra do Luar, de autoria de Walter Franco. 
taçáo em TCI que, conforme temos acompanhado no trabalho que fazemos, provoca um turbilhão de emoçóes, lembranças, que favorecem um reposicionamento diante da vida.

Para compreender o significado da capacitação em TCI, escolhemos uma abordagem qualitativa, realizada através de conversaçóes dialógicas entre a pesquisadora (Reis) e os participantes da pesquisa. As pesquisas qualitativas são exploratórias, ou seja, estimulam os entrevistados a pensarem livremente sobre um tema ou conceito. Assim, ela evidencia as experiências pessoais, característica que contempla os requisitos deste trabalho. Além disso, dada a natureza dessa investigação, centrada no campo do significado, as entrevistas foram realizadas como conversas dialógicas em torno de alguns temas de interesse para esta pesquisa.

Foram entrevistados terapeutas comunitários que participaram da capacitação em TCI no formato em vigor desde 2012, de acordo com as orientaçóes da ABRATECOM, conforme descrito na parte introdutória deste artigo. Todos eles eram integrantes de uma turma do polo formador CAIFCOM do ano de 2013. Dos 24 terapeutas em formação, sete (07) participaram da pesquisa, sendo seis (06) do sexo feminino e um do sexo masculino, com idades entre 29 e 51 anos, todos servidores públicos municipais, sendo um fisioterapeuta, duas nutricionistas e quatro psicólogas. O grupo foi definido a partir da aceitação e interesse em participar da pesquisa.

Como se tratava de uma pesquisa envolvendo seres humanos, esta investigação foi submetida àaprovaçáo da Plataforma Brasil e aprovada sob o Parecer CEP no1.154.934.

Neste trabalho foram realizadas entrevistas semiestruturadas de base dialógica, contendo algumas questôes temáticas norteadoras.. Embora houvesse alguns pontos previamente definidos, as entrevistas apresentaram-se mais como uma conversa, num interjogo de perguntas e respostas e, de tempos em tempos, uma checagem do entendimento da pesquisadora sobre o que o participante gostaria que fosse compreendido. Como as entrevistas foram gravadas, antes de seguirmos na construçáo de inteligibilidade das conversas, transcrevemos as gravaçốes e as submetemos àuma averiguação por parte dos participantes em relação ao conteúdo transcrito.

As questóes norteadoras foram 15, todas elas referentes aos propósitos da investigaçáo e são apresentadas a seguir: 
a) Qual era o contexto da sua vida antes de ingressar no curso? (Contexto de vida no momento de início do curso)

b) Por que aceitou participar deste Curso? ( $\mathrm{O}$ que lhe chamou a atenção na proposta)

c) Você tinha expectativas em relação ao curso? Quais eram? (Expectativas iniciais)

d) Que lembranças você tem do Curso? Em relação à metodologia, ao formato do curso, ou outras? (Aspectos relevantes para o participante)

e) Quais os momentos marcantes que você viveu durante o curso? Por que foram marcantes? (Momentos marcantes)

f) Você percebeu mudanças pessoais durante o curso? (Efeitos do curso)

g) Quais foram as mudanças pelas quais você passou durante esse curso e que atribui e/ ou relaciona ao curso? (Apresentação dos efeitos)

h) Você poderia me contar o que considera que foi importante no curso para que essas mudanças acontecessem? (Compreensão do significado do curso)

i) A que você atribui essas mudanças? (Entendimento dos participantes)

j) Você teria algum história a contar que ilustre essas transformações que você teve durante o curso? (Apresentação pessoal)

k) Que diferença fez na sua vida ter feito essa capacitação? (impacto do curso)

l) Quais momentos marcantes de sua jornada como terapeuta comunitária(o) você daria destaque e por que? (Momentos marcantes como terapeuta comunitária(o))

m) O que esses momentos dizem sobre o que você valoriza na vida como pessoa e como terapeuta comunitário(a)? (Valores relacionados)

n) Se você encontrasse uma pessoa que está iniciando ou deseja iniciar o curso de TCI, o que você diria e ele (a)? (compartilhamento dos resultados pessoais) 
o) Se você pudesse pensar na sua formação como terapeuta comunitária(o) como uma imagem e metáfora, que imagem ou metáfora você consideraria? (Construindo sentido)

\section{Construção do significado}

Digo: o real não estána saída nem na chegada: ele se dispóe para a gente é no meio da travessia.

(Guimarães Rosa)

Para efeito de compreender o significado da capacitação em TCI na vida dos terapeutas comunitários, as entrevistas foram ouvidas, transcritas, referendadas pelos participantes e lidas exaustivamente pela pesquisadora (Reis). Nesta trajetória, momentos marcantes da conversa foram ressaltados pela pesquisadora, tomando como referência as questôes norteadoras. De acordo com a poética social (GUANAES; JAPUR, 2008), cabe àpesquisadora deixar-se tocar pelo que ouviu dos participantes e destacar os momentos marcantes para a construção do sentido para o tema em questão:

$\mathrm{Na}$ prática da poética social, a linguagem do pesquisador não éafirmativa ou explicativa, mas alusiva, parcial e exploratória [...] Parte-se do princípio de que um texto científico não é, em si mesmo, significativo. Éno diálogo com outras vozes que este ganha sentido, podendo então ser construído como uma opção discursiva útil àcriação de novos modos de ação do mundo (GUANAES; JAPUR, 2008, p.119).

A seguir, são apresentados trechos significativos dessas conversas com os sete participantes para cada uma das questôes, intercalada com nossas reflexôes, na busca do entendimento do significado da capacitação em suas vidas.

Iniciamos a conversação dialógica com uma questão a respeito do contexto da vida pessoal e profissional, uma vez que buscávamos compreender o significado transformador do curso na vida dos terapeutas comunitários em formação. Para isso, era importante ter conhecimento sobre como estava a vida de cada um e cada uma antes do início do curso. Pelas respostas apresentadas, para cada participante a oferta do curso vinha em momentos diversos, como expresso nas falas abaixo. 
Os participantes tiveram sua identidade preservada, para isso foram utilizados codinomes:

Tigresa: "Estava passando por muitas coisas ao mesmo tempo e estava meio insegura.".

Farol: "[...] eu queria mais ferramentas, já que eu gosto de trabalhar com grupo, que outra ferramenta eu poderia estar utilizando $[\ldots] "$.

Casulo: "Estava desanimada pensando em mudar de setor no trabalho.”.

Antakarana: "Não estava bem e atravessando dificuldades no trabalho.”.

Constatamos que, da insegurança e incerteza quanto ao momento de vida pessoal ou profissional, à busca de ferramentas, a capacitação veio num momento de ampliação de horizontes. Iniciar um curso nestes momentos da vida, caracterizou-se como busca de possibilidades, mais ou menos definidas pelos participantes.

Em relação à questáo "Por que aceitou participar deste curso?, diversas foram as motivaçóes que os fizeram participar. Abaixo, reproduzimos trechos das conversaçóes que explicitam os motivos para se integrarem a essa jornada de tornarem-se terapeutas comunitários.

Buscando compreender o sentido das diferentes motivaçôes, percebemos que dois participantes aceitaram participar porque jáconheciam o criador da TCI e a sua metodologia:

Antakarana: "Eu jáconhecia Adalberto Barreto desde década de 90.

Casulo: "Já tinha ouvido o Adalberto Barreto".

Outros três participantes vieram em busca de novas ferramentas.

Farol: "[...] na expectativa de uma ferramenta [...]".

Tigresa: "[...] buscando ferramentas novas de trabalho [...]".

Ostra: "Aceitei participar a fim de conhecer essa abordagem [...]".

Uma foi trazida pela sua vontade em fazer cursos e ainda uma outra veio sem saber do que se tratava:

Águia: "O que me motivou foi minha vontade de fazer curso [...]" Pérola: "[...] acho que foi tudo sem querer [...] não era para eu ser chamada para fazer o curso [...]"

Embora com motivos diversos, um aspecto foi comum entre os participantes: a disponibilidade em fazer parte dessa viagem interna. 
Notamos que alguns já vem com algum conhecimento prévio; outros, na busca de instrumentalizaçáo para o trabalho que fazem; outros vem por vir, por se tratar de um curso e por ser indicado para algo que nem sabia do que se tratava.

Uma outra questão abordada no diálogo estabelecido entre a pesquisadora e os participantes da pesquisa foi conhecer quais as expectativas em relação à capacitação em TCI. Assim como na questão anterior, onde foram diversas as motivaçóes para participarem deste curso, aqui também as expectativas eram diversas.

Em relação às expectativas, encontramos alguns participantes em busca de novas ferramentas, como evidenciam as falas:

Farol: "A expectativa era eu conseguir [aqui Farol se refere a conseguir a vaga para participar do curso], eu não tinha ideia exata da extensáo [...] seria muito legal para a gente que trabalha em comunidade."

Ostra: "A minha expectativa, era conhecer essa abordagem de trabalho $[\ldots]$ "..

Já outros esperavam ver a aplicabilidade prática de uma metodologia não tão estranha, como foi o caso de Antakarana:

"Minha expectativa era colocar em prática as coisas que eu játinha ouvido."

Outras não traziam expectativas iniciais e uma outra vinha com a expectativa do curso ser uma terapia:

Águia: “[...] acho que eu não tinha muita expectativa [...]"

Pérola: "Na verdade eu fui muito ansiosa [...] Então aí você fez as dinâmicas no começo [...] Superando todas nossas expectativas $[\ldots] "$

Tigresa: "Minha expectativa era de terapia [...]"

Casulo: "Não deu muito tempo de criar expectativa, não tinha expectativa."

Como podemos ver, desde não ter expectativas a buscar no curso uma terapia, as motivaçóes distintas configuram a heterogeneidade de um grupo que se forma ao acaso. Obviamente essa diversidade acaba fazendo com que o processo em desenvolvimento passe por uma relação de conhecimento, reconhecimento e descoberta para cada participante. 
A partir da questão que aborda as memórias guardadas sobre o curso, aprofundamos nossa trajetória na busca da compreensão do significado da capacitação na vida dos terapeutas comunitários.

Como foi abordado anteriormente, o curso de TCI contempla encontros presenciais, onde são abordados os aspectos teórico-práticos da metodologia junto com as vivências terapêuticas. Além disso, também inclui a prática da TCI junto às comunidades e também nos encontros presenciais, durante a capacitação. Assim, destacamos como notáveis os seguintes aspectos:

Em relação à metodologia do curso, todos os participantes lembraram-se das vivências, realçando sua importância no processo de formação do terapeuta comunitário:

Águia: "Gostei das vivências [...]"

Antakarana: "[...] a questão das vivências."

Farol: "As vivências mexeram com a gente [...]"

Tigresa: "[...] gostei da forma como a gente aprendeu; [...] com vivências"

Ostra: "[...] através de vivências [...]"

Casulo: "Lembro-me mais das vivências [...]"

Pérola: "Das vivências, é o que mais marcou".

Esse resultado destaca a importância da capacitação em TCI, para além dos conteúdos programáticos. Por unanimidade os participantes referiram-se às vivências. Outros participantes destacaram o formato leve do curso, com a teoria e prática embasando todo o trabalho, além da importância da prática das rodas de TCI durante a capacitação, para internalizar a dinâmica do processo:

Águia: “[...] Paulo Freire, gostei da parte de educação, gostei das rodas [referindo-se as rodas de TCI], acho que foi a melhor forma de aprender nas rodas na comunidade [...]"

Antakarana: "Não era cansativa e o teórico era passado de um jeito que era aplicado na prática [...]"

Ostra: "[...] o trabalho com os cuidadores, através de vivências [...] Em paralelo a isso, a técnica a teoria que embasa todo o trabalho."

Outro aspecto abordado foi a condução de todo o processo, transmitindo segurança na coordenação das rodas de TCI. Em outras palavras, o processo formativo foi desenvolvido de forma a criar 


\section{O significado da capacitação em terapia comunitária integrativa na vida dos terapeutas comunitários}

empoderamento e liberdade:

Farol: “[...] a turma muito boa também e você soube conduzir $[\ldots] "$

Tigresa: "[...] gostei da forma como a gente aprendeu; porque não foi de uma forma teórica cansativa ou chata foi bem legal, [...] dinâmicas."

Assim, pudemos compreender a importância atribuída pelos participantes da proximidade entre teoria e prática e das práticas de ensino serem realizadas de forma cuidadosa. Como diz o ideário freireano, a educação não pode ser desvinculada dos contextos de vida e também pressupóe que se dê nas relaçóes de diálogo e afeto.

Dando continuidade a nossa viagem em busca do sentido da capacitação em TCI na vida do terapeuta comunitário, nessa questão abordamos dois aspectos:

1 - quais os momentos marcantes durante o curso?

2 - por que foram marcantes?

Novamente as vivências foram citadas por quase a totalidade de participantes, revelando a sua importância no processo de construção da identidade de terapeuta comunitário:

Águia: "Os momentos marcantes dos quais me recordo referem-se à atividade em que buscamos nossa criança interior [...]"

Antakarana: "As vivências [...]"

Farol: "[...] as dinâmicas de vivências e de cuidados com o outro foram marcantes $[. .$.$] "$

Ostra: "As vivências, gostei muito de algumas, não sei o nome."

Casulo: "Considero que foi muito marcante ter colocado um tema na roda [...] Outro momento, [...] onde pudemos nos colocar no lugar de nossos pais."

Pérola: "As vivências foram os momentos marcantes."

Esses resultados vêm reafirmar a importância dada pela ABRATECOM às vivências nas capacitaçóes em TCI. O espaço dedicado a um autoconhecimento e àformação de vínculos de confiança e afeto entre os participantes do curso, parecem ser de importância especial durante a formação.

Outra questão relevante que as falas mostraram diz respeito àprática das rodas de TCI dentro do curso, realçando a importância da vivência prática da TCI durante o processo de formação do ser 
terapeuta comunitário:

Águia: "Os momentos marcantes dos quais me recordo [...] as rodas que participei [...] quando fui terapeuta durante o curso de formação $[. .$.$] ”$

Tigresa: "Foram os momentos das rodas de terapia comunitária que fizemos entre nós do curso [...]"

Casulo: "Considero que foi muito marcante ter colocado um tema na roda $[\ldots]$

Pérola: "[...] As rodas em que participei e expus minhas experiências também foram muito importantes."

Portanto, a realização de rodas de TCI durante a capacitação, mais do que ilustrar a metodologia, favorece uma aprendizagem transformadora. Assim, sentir na pele o impacto de uma roda de TCI, consolida a credibilidade desta ferramenta como uma ação de significado transformador.

Um outro aspecto que aparece é a importância da convivência com o grupo, ainda que o curso não tenha sido desenvolvido no formato de imersão. No caso específico dessa turma, o grupo passava metade do dia junto, inclusive fazendo várias refeiçôes no coletivo (caféda manhã, almoço e lanche da tarde). Acreditamos que isso contribuiu para a construção da confiança entre os integrantes do curso, conforme uma das participantes relatou em sua fala: "As vivências, e a convivência com o grupo, a construção da confiança e de redes de apoio foram o melhor." (Antakarana).

Em relação à segunda parte da questão, ou seja, porque os momentos foram marcantes, a maioria dos participantes revelou a importância das vivências para o autocuidado, para o reencontro com a própria história e a possibilidade de ressignificá-la. Além disso, conforme jámencionado acima, reforçaram a importância da convivência com o grupo para a construção da confiança e de vínculos fortalecendo a rede de apoios:

Águia: "[...] foi muito bom ter revisitado minha criança e dar um pouco de amor a ela que por muitas vezes deixou de receber [...] e quando fui terapeuta durante o curso de formação o que auxiliou no empoderamento para esse novo desafio que estava a nossa frente.

Antakarana: "As vivências, e a convivência com o grupo, a construçâo da confiança e de redes de apoio foram o melhor." 
Farol: "[...] as dinâmicas de vivências e de cuidados com o outro foram marcantes, porque me fizeram refletir sobre o quanto nós, trabalhadores em saúde, também precisamos desacelerar e atéparar algumas vezes, para repensarmos o processo."

Ostra: "Foram marcantes, por que pude entrar em contato com sentimentos e sensaçóes que contribuíram para que pudesse reorganizá-las internamente."

Casulo: "[...] Outro momento, foi a dinâmica onde pudemos nos colocar no lugar de nossos pais. Pude perceber o quanto estamos conectados e o quanto deles vive em mim."

Pérola: "Ser acolhida e fortalecida foi especial."

Outro aspecto relevante apontado por alguns dos participantes diz respeito à prática das rodas de TCI durante a capacitação, seja pelo aprendizado da metodologia, seja pela possibilidade de fazer a sua terapia junto com o curso:

Casulo: "Considero que foi muito marcante ter colocado um tema na roda, a forma com que foi tratado, o respeito dos demais participantes [...]"

Tigresa: "Foram os momentos das rodas de terapia comunitária que fizemos entre nós do curso onde pude trabalhar algumas questóes pessoais."

Perguntamos sobre o efeito transformador da capacitação com uma questão aberta a respeito de mudanças pessoais durante do curso, em direçâo ao seu significado na vida do terapeuta comunitário.

As falas abaixo evidenciam que o curso de capacitação em TCI possibilitou mudanças na vida pessoal e profissional dos participantes:

Águia: “[...] o curso me ajudou a crescer [...] ver que de certa forma eu consegui ajudar alguém sendo terapeuta comunitária, pra mim isso fez uma grande diferença na minha vida."

Farol: "Eu percebi, mas como estava já em terapia no paralelo, talvez não tenha sido táo impactante, mas veio a somar, contribuir." Tigresa: "Em tudo. Autoconhecimento."

Ostra: "A mudança que percebi que tornei mais suave, mais confiante em mim."

Casulo: "Minhas mudanças foram no modo de olhar, tanto profissional ou olhar pra mim."

Pérola: "A minha maior transformação foi a ansiedade." 
Podemos considerar aqui, especialmente na fala de Águia, o benefício que temos ouvido informalmente que, ao cuidarmos do outro, estamos também cuidando de nós. Épossível aprender com nossos alunos, com a comunidade, sempre que estivermos abertos àreflexão. A capacitação em TCI promove rotineiramente a reflexão, conforme apresenta como uma sexta e última etapa, a apreciação sobre a roda que acabou de ser realizada, focando nas açóes do terapeuta e nos aprendizados possíveis.

Ao aprofundar sobre as mudanças oportunizadas pelo curso, vamos ampliando nossa tessitura sobre o significado do curso na vida do terapeuta comunitário. As falas dos participantes vão nos conduzindo nessa teia.

Todos os participantes apontaram mudanças pelas quais passaram durante o processo de formação do terapeuta comunitário. $\mathrm{O}$ que há em comum, de acordo com nosso entendimento, é que a totalidade dos participantes se permitiu revisitar sua história e ressignificá-la, a partir das vivências e rodas de TCI. Outro aspecto apontado pelos participantes foi em relação ao formato e a condução do curso:

Águia: "A forma como o curso foi conduzido [...] as vivências da massagem, do toque do abraço, de volta àcriança, isso daífez grande diferença pra mim."

Antakarana: "Percebi o quanto estava mudada depois de ter passado por rodas e vivências [Aqui ela se refere àsua escuta sem julgamento]."

Farol: "[...] eu acho que ali, esse tempo da formação me propiciou o momento de parar e lembrar de algumas coisas, não que eu as tivesse esquecido, mas eu játinha dado por passado."

Tigresa: "[...] acredito que me tornei mais humana."

Ostra: "Éo sair do racional e olhar para as emoçóes, para as experiências, aprendizagem e o aspecto sadio/saudável de cada ser humano."

Casulo: "[...] foi a facilidade de trabalhar com grupo [...] a aproximação da família."

Pérola: "Minha maior transformação foi a ansiedade."

$\mathrm{Na}$ questáo sobre o que considera que foi importante no curso para que essas mudanças acontecessem, mergulhamos um pouco mais no universo particular de cada participante, onde as falas revelam um pouco como perceberam essas mudanças: 
Águia: "De ver o ser humano de forma diferente [...] havia sempre pessoas diferentes com histórias muito parecidas."

Antakarana: "Aprender a escutar e não julgar."

Farol: "[...] propiciar um ambiente de confiança entre os colegas e a tua conduçâo que permitia que a gente falasse.."

Tigresa: "Trabalho que foi feito com a gente de dentro para fora, de fora pra dentro."

Ostra: "Assumir e reconhecer os sentimentos, a história de vida $[\ldots] "$

Casulo: "Uma mudança em mim mesma foi o fato de ter que cantar pra motivar."

Pérola: "Reencontrar a minha criança."

Olhando para cada resposta podemos notar que cada um dos participantes foi tocado, ou poderíamos dizer, capturado por um aspecto. Enquanto um participante ressalta a forma como o curso foi conduzido, os demais abordaram questôes mais particulares, como o reencontro com sua criança e sua história, confiança em si e no seu potencial, mudança no olhar e a possibilidade de olhar para dentro. Parafraseando a canção de Walter Franco, podemos dizer que, constituir-se em terapeuta comunitário, é "afinar o instrumento, de dentro para fora, de fora para dentro."

Após tecermos considerações sobre as transformações percebidas, levantamos outra questão importante para a construção do significado da capacitação na vida do terapeuta comunitário: a que vocêatribui essas mudanças? A partir das falas dos participantes, esperamos acrescentar mais algumas peças nesse mosaico polifônico.

Cada fala apresenta uma faceta distinta a respeito do porquêdas mudanças, pelo olhar de quem passou pelo processo. Um participante atribuiu as mudanças ao formato do curso como um todo, mas destaca as vivências em sua fala:

Outro aspecto destacado, condizente com o que salienta Foucault (2004) foi a importância de cuidar de si para melhor cuidar do outro:

Tigresa: "[...] a gente pode estar ajudando o outro após cuidar de nós mesmos, após nos compreendermos."

Também cabe destacar a descoberta feita por um participante em relação àimportância de se sentir acolhido, escutado e não julgado:

Antakarana: "[...] percebi que a TCI funciona, as pessoas voltam, fala do seu sofrimento porque percebem que não são julgadas." 
E, por último, mas não menos importante, a humildade, aliada àconfiança em si, no outro e no grupo:

Águia: "Você não é a estrela principal."

Farol: "A certeza de que podíamos falar, nos entregar [...]"

Aqui retomamos às lembranças, desta vez para episódios que testemunhassem as transformaçóes ocorridas, decorrentes da capacitação em TCI. Com essa questão, pretendíamos que, ao revisitar essas cenas, os participantes ampliassem sua consciência sobre essas mudanças.

Ao entrar no universo singular dos participantes pelas suas falas, percebemos que quase metade deles relataram que, reencontrar-se com sua história, através das vivências terapêuticas e das rodas realizadas durante o curso, colocou em destaque o quanto se transformaram durante a capacitação:

Antakarana: "Em casa à noite meu companheiro colocou a mão na regiấo dos rins onde fiz cirurgia, chorei muito e ali percebi o quanto eu tinha mudado.”

Tigresa: "[...] a primeira coisa maluca eu acho, que foi o segundo dia quando você fez a história do nome. Aquilo lá já começou a mexer, depois a questão minha com um familiar, com o meu irmão $[\ldots]$ "..]

Pérola: "Acho que foi aquela vivência [...] aquela de se colocar no lugar da mãe do pai e depois o que eu carrego, acho que foi a que mais mexeu comigo."

Podemos notar que as transformaçóes foram apontadas em momentos muito especiais de aproximação aos contextos significativos de suas vidas. Um curso meramente acadêmico, talvez náo teria favorecido transformaçóes tão intensas como essas.

Já para outra parte do grupo, a transformação ocorrida foi perceber-se mais confiante em si mesmo.

Águia: "Teve uma mudança [...] eu ter participado dos grupos de talentos, show de talentos, conseguir ser eu mesma.."

Outros participantes perceberam mudanças em sua forma de conduzir os grupos em seu trabalho.

Farol: "Eu me senti mais seguro trabalhando com o sofrimento deles [...] Hoje eu me relaxo mais, consigo lidar melhor com isso $[\ldots] "$

Casulo: “[...] eu não preciso dar respostas, com isso posso me soltar, esperar que o grupo traga as respostas." 
E um outro não destacou nenhum episódio em particular, mas o processo de formação como um todo.

Ostra: "Não teve um episódio, foi o conjunto, foi o processo."

Ao serem questionados sobre que diferença a capacitação em TCI fez em suas vidas, os participantes destacaram aspectos importantes, como nos trechos abaixo: "Eu digo que os defeitos não ficaram melhores, que os medos também, mas aprendi melhor saber que eles existem, mas não assustam tanto." (Águia).

Ao entrar em contatar com seus medos e defeitos e perceber que, apesar deles ainda existirem, você pode aprender a lidar com eles, pois não assustam mais, podemos considerar que Águia teve aumentado seu sentido de agência, empoderando-se para fazer frente às suas dificuldades. Assim, ela pode navegar em direção aos seus projetos, apesar dos seus medos.

Outro participante destacou a importância da valorização da pessoa: Antakarana: "Percebi a importância de valorizar a pessoa como ser humano.”.

Já para outro, uma nova abordagem para acolher o sofrimento da comunidade. Farol: "Ele foi muito importante como uma ferramenta pra mim eu estava usando não sóno grupo da terapia mas em grupos vários grupos da comunidade."

Outro aspecto destacado foi o empoderamento pessoal, a autoaceitação, aceitação e compreensão do outro, expresso na fala da participante: Tigresa: "Aprendi a me aceitar; aprendi como compreender o outro. E como o empoderamento faz a diferença."

Para Ostra: "Este curso fez uma diferença na minha vida, na prática profissional, estou mais compreensiva e tolerante com as pessoas, cada um tem a sua fase, o seu momento.”

Essa frase demonstra mais compreensão consigo e com os outros, nas diferentes fases e momentos em nossas vidas.

$\mathrm{Na}$ fala de Casulo: "[...] pude me conhecer melhor, minhas potencialidades, meus medos e minhas pérolas.”. Podemos observar a importância atribuída ao autoconhecimento, como também sair do anonimato para a visibilidade.

E, o depoimento de Pérola: "Nossa!!! Preciso falar mais??? Eu me sinto melhor hoje." evidencia seu sentimento de satisfação com sua forma atual de estar no mundo, possivelmente, com uma autoestima melhor. 
Quando questionados a respeito dos momentos marcantes enquanto terapeuta comunitário, observamos que cada participante aponta um aspecto distinto.

Para Águia, a roda continua dando frutos mesmo depois do seu final: "Acho que foi numa roda... Todas são especiais, mas foi uma roda especial em que uma senhora chegou muito triste e depois a gente a viu saindo sorridente, voltou outras vezes."

No entendimento de Antakarana, a construção de vínculos foi o mais marcante, conforme expresso em sua fala: "Quando vejo a construção das redes de apoio, o quanto as pessoas são solidárias [...]"

Para Farol "[...] o curso foi muito prático na aplicabilidade, então, hoje, faz parte no grupo de trabalho semanal atividades da terapia comunitária; hoje está incluída no cronograma de trabalho.”

Ou seja, a aplicabilidade do curso se mostrou conforme a TCI foi incorporada àrotina de trabalho e na ampliação de espaços na comunidade.

$\mathrm{Na}$ fala de Tigresa percebemos a importância do curso no fortalecimento da autoestima e do empoderamento pessoal: "Aquela roda que a gente fez com 80 pessoas que eu consegui fazer o acolhimento que adorei. Eu achei que ficaria com medo mas gostei muito, depois na avaliação, eu me senti realizada comigo mesma e com a equipe."

Um momento marcante apontado por Ostra foi a importância de contatar a emoção, falar de si, ser acolhido sem críticas: "O quanto é importante o espaço de poder falar de si, de suas vivências e emoçôes, ser acolhida sem críticas, isso permite que as pessoas percebam que são humanos os seus sentimentos."

Para Casulo, a resolutividade das rodas foi o que mais chamou a atençáo, como podemos observar em seu depoimento: "Faço rodas com servidores em reabilitação funcional, e a cada roda recebemos devolutivas do quanto às rodas tem sido importante no processo da reabilitação e na vida dos participantes."

O olhar de Pérola nos alerta para a importância da escuta amorosa, do acolhimento, do sentido da humanidade em cada ser, da simplicidade da metodologia, sem ser simplista: "[...] um rapaz que eu lembro quando ele entrou no CAPS com suspeita de esquizofrenia, super jovem (19 anos) estava se entupindo de remédio e hoje está trabalhando buscando coisas diferentes." 
Ao questionar cada participante sobre o que poderia ser importante para ele, ou seja, o que lhe era dado como valor, compreendemos que, um dos valores apontados, por Águia foi a escuta atenta e respeitosa. Ao dizer que "o ser humano precisa ser ouvido e que tem gente que precisa aprender a amar”, Águia ressalta a importância de uma escuta dialógica, deixando o outro surgir na sua singularidade.

Para Antakarana, fica explícita em sua fala a importância de se compreender o contexto, para evitar julgamento: "valorizo o olhar sobre o ser humano sem o dualismo e o reducionismo [...] e as rodas ajudam que essa percepção se amplie e a solidariedade e a humanidade estejam na frente da violência."

Já Farol, destaca a valorização do saber da experiência de vida e o reconhecimento de sua humanidade expressos em sua fala:

\begin{abstract}
“Toda semana tem várias questôes que as pessoas colocam que eu me identifico e, eu não percebi e às vezes começa a mexer comigo isso também... daí, a gente vê que não são muito diferentes as experiências que eles vivem, e que eu vivo; somos todos humanos."
\end{abstract}

$\mathrm{Na}$ fala da Tigresa foi dado destaque à importância do vínculo e do acolhimento: "Como é bom ser acolhido pela sua família, amigos, sociedade. Eu valorizo muito a humanização, sensibilidade, empatia."

Outras questôes foram abordadas por Ostra, como a valorização da cultura, do cuidado, da ética e da convivência: "Respeitar a história de vida de cada um, sua origem, seus valores, suas tradiçóes e costumes e se permitir a aprender também com os outros, numa relação de troca."

Ser mais acolhedora, amorosa, honrando a experiência do outro e reconhecendo o seu valor como ser humano como nos fala Pérola:

"Acho que a de ser mais humana, de não ver o paciente só como paciente, mas como um ser humano... hoje eu percebo então assim que consigo acolher mais."

Quando questionados a respeito do que diria a alguém que estivesse iniciando, ou desejando participar de um curso de TCI, alguns participantes demonstraram interesse em compartilhar esse saber, recomendando a capacitação para outras pessoas: 
Águia: "Demorou... Por que você não fez ainda?????????"

Antakarana: "Faça o curso..."

Farol: "Não só comece a fazer o curso como se entregue a ele... Primeiro porque vai ter um crescimento pessoal e a possibilidade de ajudar o outro é fenomenal!"

Tigresa: "Faça, melhor experiência que você vai ter na vida com certeza!"

Ostra: "Incentivaria a fazer a TCI, ela agrega, contribui e isso é bem positivo."

Casulo: "Faça."

Pérola: "Já encontrei e estou insistindo para que ela faça o Curso porque é maravilhoso."

Portanto, para todos eles, a capacitação em TCI significou uma experiência de vida significativa e que poderia ser útil para outras pessoas.

Para encerrar a entrevista foi proposto a cada participante que, a partir da experiência vivenciada na capacitação em TCI, buscasse uma imagem ou uma metáfora, para representar esses momentos. Reproduzimos, a seguir, as imagens ou metáforas apresentadas pelos participantes. Talvez tenha ficado uma curiosidade quanto àescolha dos nomes dos participantes. Cumpre dizer que os nomes: Águia, Antakarana, Farol, Tigresa, Ostra e Casulo foram escolhidos justamente pelas metáforas e imagens que os participantes ofereceram. Assim:

Águia: "Acho que a imagem que me vem a mente éde um pássaro que voa para buscar alimento e volta para alimentar aqueles que necessitam de sustento."

Antakarana: "Somos todos UM. Um Antakarana."

Farol: "Um Farol, talvez. Que ilumina e orienta a direção, mas não éele quem faz o percurso individual."

Tigresa: "Penso num tigre correndo numa floresta, livre, belo e forte para as adversidades."

Ostra: "Uma ostra se abrindo e permitindo que a linda pérola apareça."

Casulo: "Um casulo. Porque o curso possibilita a metamorfose do que estava latente."

Pérola: "A pérola. A fabula da pérola representa bem a minha transformação." 


\section{Consideraçóes finais}

Cada criatura é um rascunho a ser retocado sem cessar.

(Guimarães Rosa)

Ao investigarmos o significado da capacitação em TCI, buscávamos entender o que acontecia no processo ao longo do curso que favorecia transformaçóes na vida do terapeuta comunitário, conforme ouvíamos em depoimentos espontâneos nos contextos de capacitaçáo nos quais estivemos envolvidas. As entrevistas revelaram um pouco sobre o que os participantes compreenderam como significativo para suas mudanças. E fica evidente que, mesmo que as motivaçóes para participar sejam diversas, o resultado acaba sendo transformador, ou seja, a pessoa sai transformada após o curso.

Diante desses resultados, entendemos a importância de compartilhar e divulgar este trabalho junto às instituiçóes que promovam cursos e atividades voltadas para o autoconhecimento e mudanças positivas nos seres humanos. Especialmente a Abratecom, e aos polos formadores, para que os mesmos se apropriem do conteúdo deste trabalho como forma de qualificar cada vez mais o processo de formação de novos terapeutas comunitários. Mais do que formar um novo profissional, a capacitação em TCI tem promovido a transformação dos participantes, conforme favorece os valores de escuta respeitosa, legitimação das diferenças, ampliação da consciência de si, enfim, não se sai deste curso apenas com mais uma capacitação.

Um ponto que consideramos importante, a partir desse estudo, seria incluir na apreciação durante o curso algumas questóes levantadas nas entrevistas que fizemos. Com essa medida poderia se maximizar a qualidade dos cursos de capacitação em TCI, além de aprofundar algumas questóes investigadas por esta pesquisa, podendo colocar em linguagem as transformaçóes pessoais que vão acontecendo ao longo da jornada de capacitação. Outra possibilidade seria fazer a investigação ao longo da capacitação, para acompanhar todo esse processo de transformação, inclusive apontando possíveis diferenças em função da diversidade cultural de nosso país. Entendemos que, tanto formadores como participantes em formação ao terem sua voz ouvida, por outros e por si mesmos, ampliariam suas possiblidades de construírem juntos essa jornada em busca da transformação. 
Desamarrar as vozes, dessonhar os sonhos: escrevo querendo revelar o real maravilhoso... Dos medos nascem as coragens; e das dúvidas, as certezas.

Os sonhos anunciam outra realidade possível e os delírios, outra razáo. Somos, enfim, o que fazemos para transformar o que somos. (Eduardo Galeano) ${ }^{5}$

\title{
THE MEANING OF EMPOWERMENT IN COMMUNITY INTEGRATIVE THERAPY IN THE LIFE OF THERAPISTS COMMUNITY
}

\begin{abstract}
With this study we intend to understand the significance of empowerment in Integrative Community Therapy (TCI) for Community therapists and how this meaning was built. For this we conducted a qualitative study building a research context prioritizing the listening community therapists about their enabling process in TCI. Seven Community therapists participated in this research. Given the nature of this research focused on the significance of the field, we conducted interviews organized as dialogical conversations around some topics of interest according to the objectives stated above. The information obtained was analyzed according to the social poetry that invites the researcher to highlight important aspects in his conversation with the participants. Understand the meaning of training in ICT to the lives of community therapists and aspects involved in these results may help to understand the impact of the enabling process for those involved, contributing to the network of trainers poles in TCI credited by ABRATECOM, Latin America and Europe.
\end{abstract}

KEYWORDS: Integrative Community Therapy. Meaning. Empowerment.

\section{REFERÊNCIAS}

ANDRADE, F. B. et al. A Terapia Comunitária como instrumento de inclusão da saúde mental na atenção básica: análise da satisfação dos usuários. In: FERREIRA FILHA, M. O.; LAZARTE, R.; DIAS,

\footnotetext{
Trecho do poema Celebração das Contradiçôes/2, do Livro dos Abraços, de Eduardo Galeano.
} 
M. D. Terapia Comunitária Integrativa: uma construção coletiva de conhecimento. João Pessoa: Ed da UFPB, 2013. p. 281-319.

BARRETO, A. P. Terapia Comunitária Passo a Passo. 3. ed. rev. ampl. Fortaleza: Gráfica LCR, 2008.

BARRETO, A. P.; CAMAROTTI, H. A Terapia Comunitária no Brasil. In: CONGRESSO BRASILEIRO DE TERAPIA COMUNitÁRIA, 1., 2003, Morro Branco, CE. Anais.. Morro Branco,CE, 2003.

BRAGA, L. A. V et al. Terapia Comunitária e Resiliência: história de mulheres. In: FERREIRA FILHA, M. O.; LAZARTE, R.; DIAS, M. D. Terapia Comunitária Integrativa: uma construção coletiva de conhecimento. João Pessoa: Ed da UFPB, 2013. p.84-106.

BRANDEN, N. Os seis Pilares da Autoestima. São Paulo: Saraiva, 1997.

CAMARGO, A. C.; FRANKLIN, R. Tempo de falar e tempo de escutar: a produção de sentido em grupo terapêutico. In: FERREIRA FILHA, M. O.; LAZARTE, R.; DIAS, M. D. Terapia Comunitária Integrativa: uma construção coletiva de conhecimento. João Pessoa: Ed da UFPB, 2013. p.46-65.

CARÍCIO, M. R et al. Terapia Comunitária: um encontro que transforma o jeito de ver e conduzir a vida. In: FERREIRA FILHA, M. O.; LAZARTE, R.; DIAS, M. D. Terapia Comunitária Integrativa: uma construção coletiva de conhecimento. João Pessoa: Ed da UFPB, 2013. p.132-158.

FOUCAULT, M. A ética do cuidado de si como prática da liberdade. In: . Ditos \& Escritos volume V: Ética, Sexualidade, Política. Rio de Janeiro: Forense Universitária, 2004. p.264-287.

GRANDESSO, M. A. Terapia comunitária: um contexto de fortalecimento de indivíduos, famílias e redes. Família e Comunidade, São Paulo, v.1, n.2, p.103-113, 2005.

GUANAES, C; JAPUR, M. Contribuiçóes da Poética Social à pesquisa em Psicoterapia de Grupo. Estudos de Psicologia, Natal, v.13, n.2, mai/ago, p.117-124, 2008. 
GUIMARÃES, F. J.; FERREIRA FILHA, M. A. O. Repercussóes da Terapia Comunitária no cotidiano de seus participantes. In: FERREIRA FILHA, M. O.; LAZARTE, R.; DIAS, M. D. Terapia Comunitária Integrativa: uma construção coletiva de conhecimento. João Pessoa: Ed da UFPB, 2013. p.320-344.

HOLANDA, V. R. et al. A Contribuição da Terapia Comunitária para o enfrentamento das inquietaçóes das gestantes. In: FERREIRA FILHA, M. O.; LAZARTE, R.; DIAS, M. D. Terapia Comunitária Integrativa: uma construção coletiva de conhecimento. João Pessoa: Ed da UFPB, 2013. p.231-251.

LAZZARINI, L. L. B.; GRANDESSO, M. Minha vida tem sentido toda vez que venho aqui: significado atribuído à Terapia Comunitária pela família do participante. In: FERREIRA FILHA, M. O.; LAZARTE, R.; DIAS, M. D. Terapia Comunitária Integrativa: uma construção coletiva de conhecimento. João Pessoa: Ed da UFPB, 2013. p.66-83.

MORAIS, F. L. S. L; DIAS, M.D. Rodas de Terapia Comunitária: espaços de mudanças para profissionais da estratégia saúde da família. In: FERREIRA FILHA, M. O.; LAZARTE, R.; DIAS, M. D. Terapia Comunitária Integrativa: uma construção coletiva de conhecimento. João Pessoa: Ed da UFPB, 2013. p.159-187.

OLIVEIRA, D. G. S; DIAS, M.D. História da Terapia Comunitária Integrativa na Atenção Básica de Saúde em João Pessoa - PB: uma ferramenta de cuidado. In: FERREIRA FILHA, M. O.; LAZARTE, R.; DIAS, M. D. Terapia Comunitária Integrativa: uma construção coletiva de conhecimento. João Pessoa: Ed da UFPB, 2013. p.254280 .

REIS, M. L. A. Intervisão: o exercício da dialogicidade na formação em Terapia Comunitária - trajetória da construção de um novo conceito. Articulando Redes Sociais, Porto Alegre, n.1, 2010.

REIS, M. L. A; SALERNO, G. TCI e a Educação: Terapia Comunitária Integrativa: uma proposta de construção do currículo escolar baseada no diálogo freireano. In: CAMAROTTI, M. H.; FREIRE, T. G.; BARRETO, A. P. Terapia Comunitária Integrativa 
Sem Fronteiras: Compreendendo suas interfaces e aplicações. Brasília: MISMEC, 2011. p.363-381.

RIQUE, M. R. Terapia Comunitária: Um encontro que transforma o jeito de ver e conduzir a vida. 2010. 134 f. Dissertação (Mestrado em Enfermagem) - Universidade Federal da Paraíba, João Pessoa, 2010 .

ROCHA, E. F; FERREIRA, FILHA, M. O. A Terapia Comunitária e as Mudanças Práticas no SUS. In: FERREIRA FILHA, M. O.; LAZARTE, R.; DIAS, M. D. Terapia Comunitária Integrativa: uma construção coletiva de conhecimento. João Pessoa: Ed da UFPB, 2013. p.108-131.

SIlVA, A. L. C; ALMEIDA, E. C. Terapia Comunitária como abordagem complementar no tratamento de depressão: uma estratégia de saúde mental no PSF de Petrópolis. In: FERREIRA FILHA, M. O.; LAZARTE, R.; DIAS, M. D. Terapia Comunitária Integrativa: uma construção coletiva de conhecimento. João Pessoa: Ed da UFPB, 2013. p.208-230.

SOBREIRA, M. V. S; MIRANDA, F. A. N. A Terapia Comunitária e suas repercussóes no processo de trabalho da Estratégia Saúde da Família: um estudo representacional. In: FERREIRA FILHA, M. O.; LAZARTE, R.; DIAS, M. D. Terapia Comunitária Integrativa: uma construção coletiva de conhecimento. João Pessoa: Ed da UFPB, 2013. p.188-206. 
